\title{
HEMOVIGILÂNCIA DAS REAÇÕES TRANSFUSIONAIS IMEDIATAS: OCORRÊNCIAS, DEMANDA E CAPACIDADE DE ATENDIMENTO
}

\author{
HEMOVIGILANCE OF IMMEDIATE \\ TRANSFUSION REACTIONS: OCCURRENCES, \\ DEMAND AND SERVICE CAPACITY
}

\section{HEMOVIGILANCE DE REACCIONES TRANSFUSIONALES INMEDIATAS: OCURRENCIAS, DEMANDA Y CAPACIDAD DE ATENCIÓN}

\author{
Marta Suzin Cercato ${ }^{1}$ \\ Mariluce Karla Bomfim de Souza ${ }^{2}$
}

\begin{abstract}
Como citar este artigo: Cercato MS, Souza MKB. Hemovigilância das reações transfusionais imediatas: ocorrências, demanda e capacidade de atendimento. Rev baiana enferm. 2021;35:e42268.

Objetivo: identificar e discutir a ocorrência de reações transfusionais imediatas, considerando o tipo de hemocomponente transfundido, demanda e capacidade de atendimento em um Hospital Universitário do estado da Bahia, Brasil. Método: estudo de caso, retrospectivo, quantitativo, realizado por meio de levantamento de registros e documentos. Análise descritiva das frequências e percentuais das ocorrências e tipologias das Reações Transfusionais, bem como da demanda e capacidade de atendimento da unidade de hemoterapia deste hospital. Resultados: frequência de 6,43\% de Reações Transfusionais imediatas/1.000 hemocomponentes transfundidos. A Reação Febril Não Hemolítica e a Reação Alérgica foram as que mais ocorreram. Maior número de Reações Transfusionais foram do grau I (97,5\%); os concentrados de hemácias $(44,1 \%)$ e de plaquetas $(41,9 \%)$ foram os hemocomponentes envolvidos na maioria das Reações Transfusionais. Conclusão: a unidade estudada mostrou capacidade de atendimento à demanda, com notificação das reações transfusionais e destaque de tais ações para contínuo aperfeiçoamento da qualidade.
\end{abstract}

Descritores: Segurança do Sangue. Reação Transfusional. Notificação. Sistemas de Informação. Serviço de Hemoterapia.

Objective: to identify and discuss the occurrence of immediate transfusion reactions, considering the type of transfused blood component, demand and care capacity in a University Hospital in the state of Bahia, Brazil. Method: case, retrospective, quantitative study, performed through the collection of records and documents. Descriptive analysis of the frequencies and percentages of occurrences and typologies of Transfusion Reactions, as well as the demand and capacity of the bemotherapy unit of this hospital. Results: frequency of $6.43 \%$ of immediate Transfusion Reactions/1,000 transfused blood components. The Nonhemolytic Febrile Reaction and Allergic Reaction were the ones that most occurred. The highest number of Transfusion Reactions were grade I (97.5\%); red blood cell concentrates (44.1\%) and platelets (41.9\%) were the blood components involved in most Transfusion Reactions. Conclusion: the

\footnotetext{
Enfermeira. Mestre em Saúde Coletiva. Enfermeira Assistencial da área hospitalar. Enfermeira assistencial na Assembleia Legislativa da Bahia. Salvador, Bahia, Brasil. http://orcid.org/0000-000 I-78|4-9540.

Enfermeira. Doutora em Saúde Pública. Professora Associada do Departamento de Saúde Coletiva I no Instituto de Saúde Coletiva da Universidade Federal da Bahia. Salvador, Bahia, Brasil. marilucejbv@yahoo.com.br. http://orcid.org/0000-0002-7895-4432.
} 
unit studied showed capacity to meet the demand, with notification of transfusion reactions and highlighting such actions for continuous quality improvement.

Descriptors: Blood Safety. Transfusion Reaction. Notification. Information Systems. Hemotherapy Service.

Objetivo: identificar y discutir la aparición de reacciones transfusionales inmediatas, considerando el tipo de componente sanguíneo transfundido, la demanda y la capacidad de atención en un Hospital Universitario en el estado de Babia, Brasil. Método: estudio de caso práctico, retrospectivo, cuantitativo, realizado a través de la recopilación de registros y documentos. Análisis descriptivo de las frecuencias y porcentajes de ocurrencias y tipologias de reacciones transfusiones, asi como la demanda y capacidad de la unidad de hemoterapia de este hospital. Resultados: frecuencia del 6,43\% de las reacciones transfusiones inmediatas/1.000 componentes sanguineos transfundidos. La Reacción Febril No-hemolítica y la Reacción Alérgica fueron las que más ocurrieron. El mayor número de reacciones transfusionales fue el grado I (97,5\%); los concentrados de glóbulos rojos (44,1\%) y plaquetas (41,9\%) fueron los componentes sanguineos involucrados en la mayoría de las reacciones transfusiones. Conclusión: la unidad estudiada mostró capacidad para satisfacer la demanda, con notificación de reacciones transfusiones y destacando tales acciones para la mejora continua de la calidad.

Descriptores: Seguridad de la Sangre. Reacción Transfusional. Notificación. Sistemas de Información. Servicio de Hemoterapia.

\section{Introdução}

A segurança transfusional e a qualidade dos hemocomponentes tornaram-se inquietação e foco de preocupação para a Hemoterapia a partir da década de 1980, devido ao surgimento da AIDS e da Hepatite C. Desde então, a segurança transfusional passa a ser necessidade mundial e norteada por processos com a finalidade de eliminar ou reduzir riscos ${ }^{(1)}$. Existe uma mobilização por parte do setor público para aprimorar as práticas, por meio da avaliação e de melhorias contínuas nos processos de trabalho e ainda da adoção de medidas capazes de monitorar e avaliar a qualidade de seus produtos e serviços ${ }^{(2)}$.

A Hemovigilância brasileira destaca-se por um conjunto de métodos de vigilância que envolve o ciclo do sangue, com a finalidade de incluir e assegurar informações sobre eventos adversos que ocorram durante o ciclo do sangue, com a finalidade de "[...] prevenir sua manifestação ou recorrência, de melhorar a qualidade dos processos e/ou produtos, de reduzir riscos no processo hemoterápico, de aumentar a segurança transfusional do doador e do receptor" ${ }^{\text {(3:3). }}$

No Brasil, a partir de 2015, através do Sistema Nacional de Hemovigilância (SNH) o escopo da hemovigilância foi ampliado, incluindo os eventos adversos em todo o ciclo do sangue, em receptores e doadores e, não apenas aqueles relativos à transfusão, passando a seguir as orientações e tendências internacionais ${ }^{(4)}$.

Com a finalidade de ampliar o conhecimento relativo à produção científica existente sobre Hemovigilância e Reações Transfusionais (RT), foi realizada uma busca nas bases Lilacs, SciELO e MEDLINE, com base em descritores selecionados - "Segurança do Sangue" (Blood Safety) e "Reação Transfusional" (Transfusion Reaction) e outros termos - "Hemovigilância" e "Incidentes transfusionais" - utilizados isoladamente e com a seguinte combinação: "Segurança do Sangue AND Reações Transfusionais", "Hemovigilância AND Reação Transfusional", considerando um recorte temporal recente de 5 anos (2013 a 2017). Assim, foram identificados 147 artigos. Após a aplicação dos critérios de exclusão, foram selecionados 39 artigos de 11 países. Desse conjunto, destacam-se alguns estudos que avaliam a frequência das reações transfusionais por tipo de hemocomponentes, associada a dados demográficos (idade, sexo, raça) e aos sinais e sintomas $^{(5-15)}$.

No Brasil, a frequência absoluta das notificações de reações transfusionais nos anos de 2002 a 2015 aumentou de 160 para 12.841 notificações/ano. O aumento dos registros a partir de 2010 deveu-se à obrigatoriedade da notificação 
das RT. No entanto, o quantitativo de subnotificações ainda é muito alto. Os parâmetros internacionais afirmam que o percentual estimado de subnotificações de RTs é de 15\%, mas, segundo a Anvisa, o parâmetro nacional não é conhecido ${ }^{(16)}$.

$O$ ato transfusional não é isento de riscos, apesar de todo o conhecimento reunido e utilizado até os dias atuais. A literatura internacional mostra que as reações transfusionais imediatas são predominantes, embora a proporção seja diferente da verificada na realidade brasileira. A notificação das reações transfusionais tem se tornado um instrumento primordial para o contínuo aperfeiçoamento da qualidade do sangue e de seus produtos, bem como da segurança do ato transfusional, o que torna o Sistema de Hemovigilância imprescindível nesse processo.

Este artigo tem por objetivo identificar e discutir a ocorrência de RTs imediatas, considerando o tipo de hemocomponente transfundido, demanda e capacidade de atendimento em um Hospital Universitário do estado da Bahia, Brasil.

\section{Método}

Trata-se de um estudo retrospectivo, descritivo, de abordagem quantitativa e que adota como estratégia de pesquisa o estudo de caso.

O campo deste estudo caracteriza-se como unidade hospitalar e ambulatorial, classificada como hospital universitário (HU), um dos que integra e atende à Rede SUS, sendo referência no estado da Bahia. A Unidade de Hemoterapia (UH) que integra este hospital é uma agência transfusional (AT) que atende os pacientes de todo o complexo hospitalar, mediante requisição de transfusão solicitada por médico. Para o funcionamento dessa AT, os gestores da Universidade e do Hemocentro Coordenador da Bahia, a Fundação de Hematologia e Hemoterapia da Bahia (Hemoba), firmaram um acordo, por meio de contrato, no qual à equipe da UH cabe, desde a gestão de hemocomponentes, no hospital, até a rastreabilidade do uso.
Para a coleta dos dados secundários, realizada entre dezembro de 2018 e abril de 2019, foram utilizados registros de 84 relatórios mensais de produtividade da UH (referentes aos anos de 2012 a 2018), além de 405 fichas de notificação de reações transfusionais (FIT) que alimentam o Sistema de Notificação da Vigilância Sanitária (Notivisa) e dados do Cadastro Nacional de Estabelecimentos (CNES). Também foram consultados documentos, dentre os quais: relatório de gestão do Hospital, relatório de Núcleo de Epidemiologia Clínica e relatório de unidade de hemoterapia. Outros documentos foram também disponibilizados pelo campo, como, por exemplo, contrato Universidade-HEMOBA, relatório técnico de inspeção sanitária, relatório de visita, livros de ocorrência e procedimentos operacionais, além de outros de acesso público.

A seleção dos dados e documentos atendeu aos seguintes critérios de inclusão: dados e registros de produção dos anos de 2012 a 2018; documentos e relatórios que se reportassem à organização e aos procedimentos para a produção da UH e relacionados com a notificação e o acompanhamento das reações transfusionais.

O software Microsoft Excel foi utilizado para a organização e sistematização dos dados coletados nas fichas de notificação e nos relatórios mensais de produtividade. Na sequência, foram produzidos gráficos e tabelas contendo número de leitos do hospital do período em análise e dados referentes aos receptores, tais como: grupo $\mathrm{ABO} \mathrm{Rh}$, idade, sexo, cor, tipo de hemocomponentes utilizados, unidade hospitalar onde a transfusão ocorreu, frequência e tipo de reação transfusional imediata ocorrida, gravidade da reação, sinais e sintomas evidenciados. Assim, procedeu-se a análise descritiva das frequências e dos percentuais das ocorrências e tipologias das RT, bem como da demanda e capacidade de atendimento dessa UH.

Cabe destacar que a referência às transfusões realizadas, refere-se, neste estudo, ao número de vezes em que foi realizada uma transfusão, 
seja de concentrado de hemácias, de pool de plaquetas, plasma fresco ou pool de crioprecipitados. Esclarece-se, quanto ao número de bemocomponentes transfundidos, que se refere ao número unitário de cada hemocomponente em cada transfusão, e não ao pool que foi produzido.

Este estudo foi desenvolvido em acordo com a Resolução n 466/2012, do Conselho Nacional de Saúde. O projeto foi submetido ao Comitê de Ética em Pesquisa (CEP) do Instituto de Saúde Coletiva (ISC) da Universidade Federal da Bahia (UFBA), Certificado de Apresentação para Apreciação Ética (CAAE) n ${ }^{\circ}$ 01605218.5.0000.5030, e aprovado pelo Parecer no 3.003.450. Também foi apreciado pelo Comitê de Ética do Hospital Universitário (HU) estudado, enquanto instituição coparticipante, sob número de protocolo CAAE 01605218.5.3001.0049 e Parecer de Aprovação no 3.100 .746 .

\section{Resultados}

Os resultados estão expostos em duas subseções intituladas "Reações transfusionais imediatas: notificações, perfil da população acometida e sua relação com os hemocomponentes transfundidos" e "Demanda e capacidade de atendimento da UH".
Reações transfusionais imediatas: notificações, perfil da população acometida e sua relação com os hemocomponentes transfundidos

Dos 62.968 hemocomponentes transfundidos nesse hospital, no período de 2012 a 2018, foram notificadas à Anvisa 405 RTs imediatas. Os hemocomponentes mais envolvidos nessas reações foram: 219 Concentrado de Hemácias $(\mathrm{CH})$, 165 Concentrado de Plaquetas (CP), 16 Plasma Fresco Congelado (PFC), 5 Crioprecipitado.

Observa-se, no Gráfico 1, a frequência das RTs notificadas por hemocomponentes no período do estudo. Verifica-se que o hemocomponente mais envolvido em reações transfusionais foi o concentrado de hemácias, seguido pelo concentrado de plaquetas. Estes dois hemocomponentes estavam envolvidos em 95\% das notificações de reação transfusional relatadas. Os dados apresentados no gráfico foram extraídos das 405 fichas de atendimento. As reações transfusionais imediatas mais notificadas à Anvisa foram: 261 Reações Febris Não Hemolítica (RFNH), seguida por Reação Alérgica (RA) com 135 casos, 8 notificações como Sobrecarga Volêmica (SCV) e 1 caso notificado de Injúria Pulmonar não Cardiogênica (Transfusion Related Acute Lung Injury - TRALI). Não houve, nesse período, observação de Reação Hemolítica (RH).

Gráfico 1 - Frequência de hemocomponente envolvido nas reações transfusionais imediatas em Hospital Universitário. Bahia, Brasil - 2012-2018

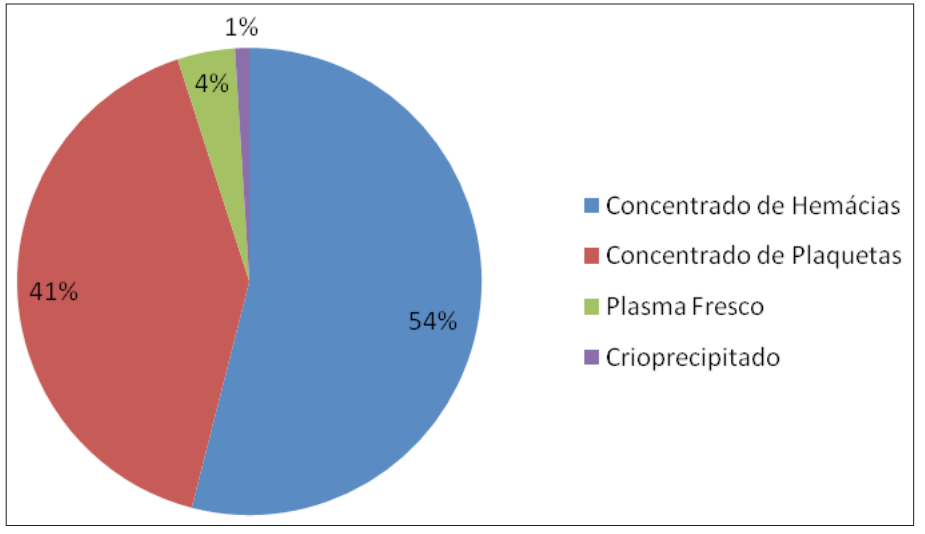

Fonte: Elaboração própria.

No Gráfico 2, pode-se verificar quais as reações transfusionais mais frequentes, conforme as notificações, sendo a Reação Febril Não Hemolítica (RFNH) a mais notificada, seguida pela Reação
Alérgica (RA). Estes dois tipos de reação transfusional representaram, juntos, 97,7\% do total. Os dados apresentados no gráfico correspondem às informações das 405 fichas de notificação. 
Gráfico 2 - Frequência das Reações Transfusionais notificadas no Hospital Universitário. Bahia, Brasil $-2012-2018$

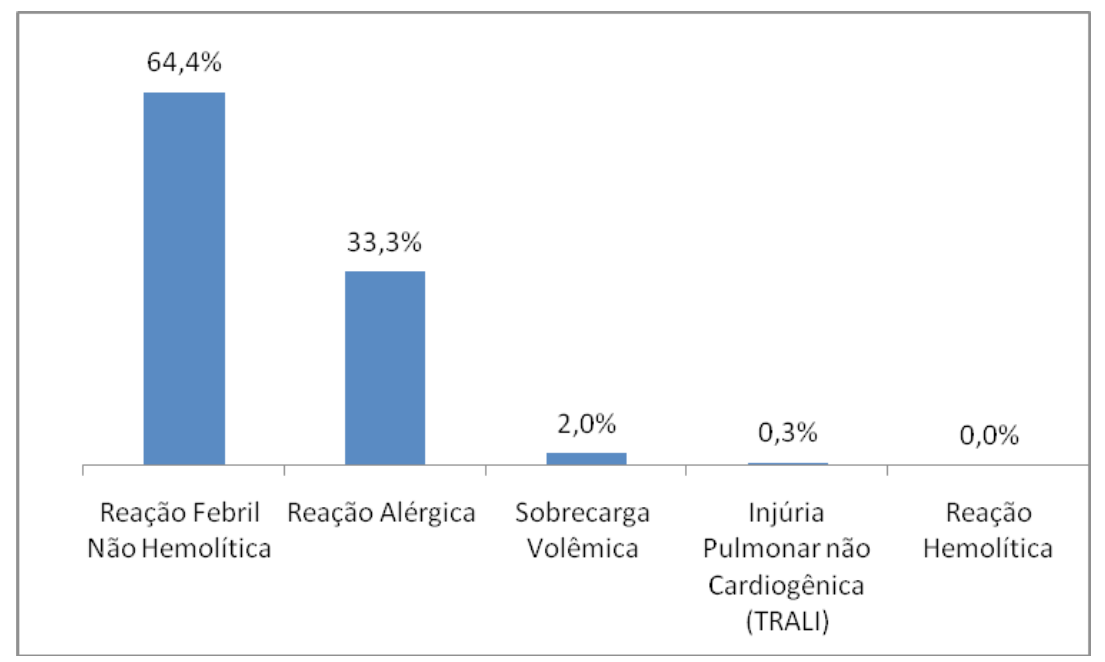

Fonte: Elaboração própria.

A Tabela 1 apresenta a frequência, em números absolutos e relativos, referente aos dados sociodemográficos de faixa etária, sexo, raça/cor dos receptores de transfusão, notificados à Hemovigilância como aqueles que relataram e/ou nos quais se observaram reação transfusional, além da gravidade com a qual a RT apresentou-se.

Tabela 1 - Caracterização das notificações encaminhadas pelo Hospital Universitário à Anvisa. Bahia, Brasil - 2012-2018. (N=405)

\begin{tabular}{lcc}
\hline Variáveis & $\mathbf{n}$ & $\mathbf{\%}$ \\
\hline Faixa Etária & & 2,2 \\
$0-9$ anos & 92 & 10,4 \\
$10-19$ anos & 72 & 17,8 \\
$20-29$ anos & 71 & 17,5 \\
$30-39$ anos & 66 & 16,3 \\
$40-49$ anos & 65 & 16,1 \\
$50-59$ anos & 43 & 10,6 \\
$60-69$ anos & 37 & 9,1 \\
70 anos e & & 51,9 \\
Sexo & 210 & 48,1 \\
Feminino & 195 & 67,9 \\
Masculino & & 15,8 \\
Raça/Cor (1) & 275 & 15,3 \\
Pardos & 64 & 0,2 \\
Negros & 62 & 0,8 \\
Brancos & 1 & 100 \\
Amarelos & 3 & 97,5 \\
Não Declarada & & 1,5 \\
Gravidade (2) & 395 & 1 \\
Grau I & 6 & 1 \\
Grau II & 405 & \\
Grau III & & \\
Total & & \\
\hline
\end{tabular}

Fonte: Elaboração própria.

(1) Na variável raça-cor não houve notificação de Reação Transfusional em indígena no período analisado.

(2) Na variável gravidade, não houve registro de Reação Transfusional no grau IV no período analisado. 
Verifica-se que não houve concentração expressiva em nenhuma faixa etária. Observa-se ainda que a menor idade de um paciente cuja RT foi notificada foi de 1 mês de vida, e a maior idade, 86 anos. Quanto à variável sexo, percebe-se que não houve prevalência de reação transfusional; sobre a raça/cor autorreferida, prevaleceu a cor parda. Identifica-se, quanto à gravidade, que RTs com grau I foram as mais notificadas. Não houve notificações grau IV, aquela em que o óbito pode ser atribuído às reações adversas.

No período deste estudo, as enfermarias/unidades onde se evidenciaram as reações transfusionais foram: enfermaria e ambulatório de hematologia, com 233 fichas; Clínicas Médicas, com 66 notificações; Unidade de Terapia Intensiva
(UTI), com 62 reações; seguidas pelas Clínicas Cirúrgicas, com 32 fichas; e, por fim, as Clínicas Pediátricas, com 12 notificações do total. Não houve notificação de ocorrência de reação transfusional imediata, por demanda espontânea ou por busca ativa, em pacientes dentro do Centro Cirúrgico.

Sinais e sintomas diferentes foram agrupados em 29 grupos distintos, sendo assinalados 611 vezes em 405 receptores-pacientes. Os 10 mais frequentemente apontados estão listados na Tabela 2. Cabe citar que foram identificados sintomas que sugeriam um agravamento do quadro clínico, como broncoespasmo (2 casos), edema agudo de pulmão (1 caso), convulsão (1 caso), creptos em base de pulmão (1 caso).

Tabela 2 - Sinais e sintomas percebidos e notificados em receptores que apresentaram reação transfusional imediata no Hospital Universitário. Bahia, Brasil - 2012-2018. (N=611)

\begin{tabular}{|c|c|c|c|c|c|c|c|c|c|c|}
\hline $\mathbf{N}^{\circ}$ & Sinais/sintomas $\quad$ Ano & 2012 & 2013 & 2014 & 2015 & 2016 & 2017 & 2018 & Total & $\%$ \\
\hline 1 & Febre & 65 & 95 & 28 & 24 & 15 & 15 & 20 & 262 & 42,9 \\
\hline 2 & $\begin{array}{l}\text { Placas eritematosas/ Placas } \\
\text { cutâneas/ Rush cutâneo/ Ardor em } \\
\text { face/ Pápulas em face e em corpo }\end{array}$ & 8 & 17 & 5 & 6 & 24 & 32 & 22 & 114 & 18,7 \\
\hline 3 & Urticária/Prurido & 9 & 10 & 4 & 14 & 17 & 18 & 21 & 93 & 15,2 \\
\hline 4 & $\begin{array}{l}\text { Dispneia/ Desconforto respiratório/ } \\
\text { Taquipneia/ Ortopneia }\end{array}$ & 4 & 1 & 2 & 4 & 10 & 6 & 5 & 32 & 5,2 \\
\hline 5 & Calafrio & 6 & 3 & 1 & 4 & 4 & 2 & 6 & 26 & 4,2 \\
\hline 6 & $\begin{array}{l}\text { Edema pálpebras/ Lábios/ } \\
\text { Região Ocular/ Periorbital }\end{array}$ & - & - & 1 & - & 5 & 5 & 7 & 18 & 2,9 \\
\hline 7 & Tremores & 4 & 3 & - & 4 & 1 & 1 & 3 & 16 & 2,6 \\
\hline 8 & Tosse/ Desconforto em garganta & 1 & - & - & - & 2 & 3 & 2 & 8 & 1,3 \\
\hline 9 & Hipertensão & 1 & - & - & 2 & 2 & - & 3 & 8 & 1,3 \\
\hline 10 & Náusea/Vômito & - & 5 & 1 & 1 & - & - & - & 7 & 1,1 \\
\hline
\end{tabular}

Demanda e capacidade de atendimento da Unidade de Hemoterapia

A UH recebe da Fundação Hemoba concentrado de hemácias, concentrado de plaquetas randômicas, pool de plaquetas e plaquetas por aférese, concentrado de plasma congelado e crioprecipitado.

No período de janeiro de 2012 a dezembro de 2018, foram realizadas 39.310 transfusões de
62.968 hemocomponentes em 6.477 pacientes (receptores).

A distribuição mais frequente por grupo $\mathrm{ABO}$ $\mathrm{Rh}$ dos receptores de hemocomponentes no HU foi o grupo com "Rh positivo". Dentre os pacientes que receberam transfusão, a maior parte era do grupo $\mathrm{O}(+)$, seguidos pelo grupo $\mathrm{A}(+)$. Os grupos menos frequentes quanto à tipagem sanguínea dos pacientes receptores foram os pertencentes ao "Rh negativo", sendo menos 
encontrados pacientes receptores do grupo $\mathrm{AB}(-)$, seguido pelo grupo $\mathrm{B}(-)$.

No que se refere ao quantitativo de transfusões por tipo de hemocomponente, verifica-se que, dentre os 62.968 hemocomponentes transfundidos, ocorreu maior número de transfusão de $\mathrm{CH}$, correspondendo a $44,1 \%$ das transfusões realizadas, seguido pela transfusão de $\mathrm{CP}$, com o quantitativo de $41,9 \%$ de infusões; logo após, o hemocomponente mais utilizado foi o PFC, sendo transfundido $12,6 \%$ do total e, por fim, $1,4 \%$ das transfusões foi de crioprecipitado.

As transfusões ocorreram em todas as unidades/enfermarias do hospital. Nesse período, especificamente, as quantidades e locais para onde foram encaminhados e transfundidos hemocomponentes corresponderam a: 36.165 , na enfermaria e no ambulatório de hematologia; 13.649, nas UTIs; 7.222, nas enfermarias de especialidades de Clínicas Médicas; 1.001, nas enfermarias de Clínicas Pediátricas; 3.137, nas Clínicas Cirúrgicas; e 1.794, no Centro Cirúrgico.

O número de leitos de hematologia, clínicos, cirúrgicos e pediátricos do hospital, no período do estudo, variou de 200 a 289; já o número de leitos de UTI oscilou entre 10 e 20, de acordo com dados do Núcleo de Epidemiologia do Hospital.

O Gráfico 3 demonstra a frequência de transfusões realizadas por unidade de hemocomponente, distribuídas pelas unidades/enfermarias de internação no período do estudo. Identifica-se que mais da metade das transfusões realizadas nesse hospital ocorreu na enfermaria e no ambulatório de hematologia e transplante de medula óssea, seguidos da UTI. A Clínica Pediátrica foi o local onde ocorreu menor número de transfusões. Os dados apresentados no gráfico correspondem às informações das 39.310 transfusões ocorridas.

Gráfico 3 - Transfusão de hemocomponentes segundo unidade assistencial no Hospital Universitário. Bahia, Brasil - 2012-2018

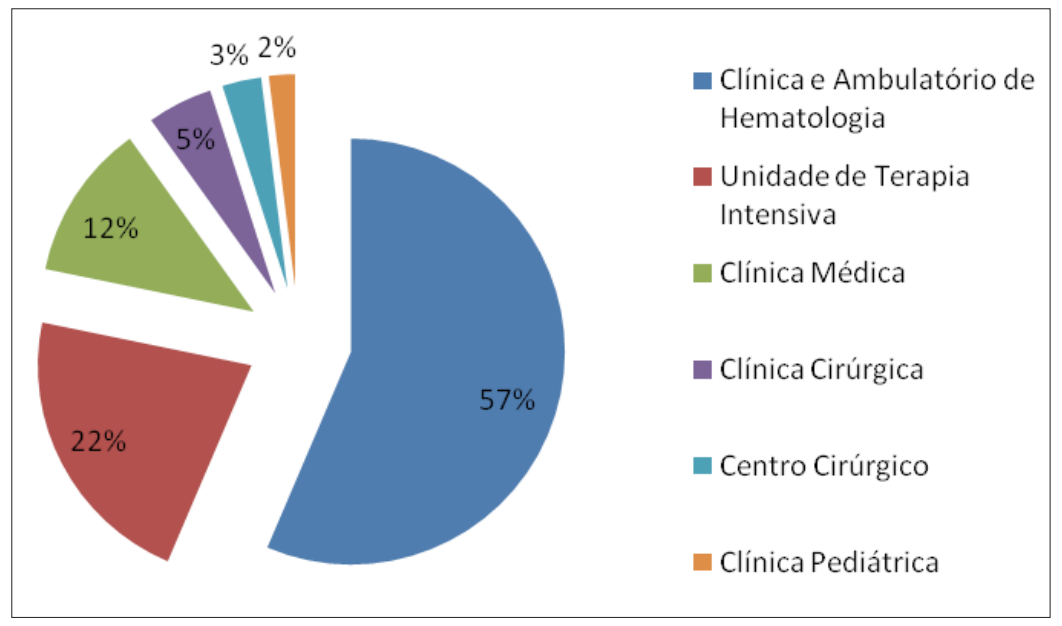

Fonte: Elaboração própria.

\section{Discussão}

A Gerência de Monitoramento do Risco da Anvisa levanta a hipótese de que a taxa de RT no país esteja mais próxima de 5 RT em 1.000 hemocomponentes, enquanto o sistema de Hemovigilância francês aponta para uma incidência esperada de três reações transfusionais em 1.000 hemocomponentes transfundidos ${ }^{(17)}$. O caso estudado notificou a frequência de 6,43 RTs imediatas/1.000 hemocomponentes transfundidos. Outros estudos ${ }^{(18-19)}$ apontam variedade nas taxas de incidência transfusional de 1,7 e 3,9 por 1.000 hemocomponentes transfundidos, respectivamente.

Quanto ao perfil de tais ocorrências no HU estudado, no que tange à variável sexo, observou-se que 51,9\% das RTs imediatas ocorreram em mulheres e 48,2\%, em homens. O Relatório de Hemovigilância da Anvisa, de $2010^{(16)}$, observa, 
de maneira geral, uma leve predominância do sexo feminino. Entretanto, cabe destacar que as diferenças entre os sexos apresentadas em estudos $^{(14,20)}$ não ultrapassaram 3\%, sendo a maioria do sexo feminino. A distribuição percentual foi igual para os sexos em estudo ${ }^{(21)}$ que descreveu a reação transfusional aguda em um serviço de transfusão brasileiro, enquanto que, em estudo sobre epidemiologia das reações transfusionais imediatas $^{(22)}$, ao contrário, a maioria das RT foram notificadas para o sexo masculino. No que se refere à variável raça/cor, verificou-se que a cor mais autodeclarada foi a parda, seguida da cor branca e da cor negra.

As reações transfusionais podem ser classificadas quanto ao tempo de aparecimento, à gravidade, à correlação com a transfusão (im-

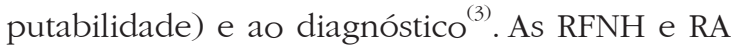
foram as duas RTs imediatas mais notificadas à Notivisa no período de 2012 a 2018, chegando a $97,7 \%$ do total de reações, concordando com o que é divulgado nos relatórios do Ministério da Saúde ${ }^{(16)}$. Em Boletim de Hemovigilância da Anvisa, há relato de ocorrência de RFNH e RA como as mais prevalentes, com taxas acumuladas de 48\% e 36\%, respectivamente, no período de 2013 e $2014^{(17)}$. No que se refere à tipologia das reações transfusionais, observou-se que as reações imediatas perfizeram a quase totalidade das notificações de reações (97\%), contra 3\% das $\operatorname{tardias}^{(23)}$.

Especificamente quanto ao tipo de RT imediata, os dados apresentados neste estudo diferem dos encontrados em estudos ${ }^{(20,22)}$ que relatam a ocorrência de maior percentual de RA e depois as RFNH. No entanto, pesquisa sobre reações transfusionais em hospital universitário ${ }^{(24)}$ relata que a RT que mais ocorreu foi a RFNH seguida pela RA.

É possível que haja subnotificação dos casos de TRALI, pois nem sempre é bem diferenciada de sobrecarga volêmica ou de falência cardíaca congestiva. Devido à similitude do quadro sintomático com outras reações adversas, muitas vezes a TRALI pode ter sido notificada equivocadamente, em alguns casos, como sobrecarga de volume ou como contaminação bacteriana, pois esta última apresenta o mesmo sintoma: calafrios $^{(25)}$.

Em relação ao tipo e à gravidade das RTs imediatas, os resultados deste estudo assemelham-se ao que é observado pelo Ministério da Saúde ${ }^{(16)}$, sendo as RFNH e RA as mais notificadas. Assemelham-se também ao encontrado em estudo realizado em hospital universitário ${ }^{(24)}$. Na análise das notificações de reações por tipo de gravidade para 2014, a Anvisa ${ }^{(17)}$ verificou que, no Brasil, a gravidade leve representou 82,6\%; a moderada, 14,3\%; a grave, 2,8\%; e o óbito, 0,3\%.

No que diz respeito às unidades/enfermarias onde ocorreram as RTs imediatas, verificou-se, neste estudo, que $57,5 \%$ foram notificadas no ambulatório e enfermaria de hematologia, logo após as clínicas médicas, seguido das UTIs. Para este fato, levanta-se a hipótese de que isso ocorreu porque o maior número de transfusões realizou-se nessas clínicas ao invés de nas UTIs. Em 2016, observou-se maior prevalência de RTs notificadas em clínica médica, seguida pela UTI/CTI e ambulatório de transfusão ${ }^{(16)}$. Percebe-se semelhança com o identificado em estudo $^{(24)}$ que relata a Unidade de Oncologia como aquela onde mais ocorreu notificação de RT, seguida pela Clínica Médica e pelas unidades críticas e semicríticas. Os menores percentuais também se assemelham aos deste estudo, sendo as clínicas cirúrgicas e as unidades pediátricas as menos notificadas. Esses resultados diferem do encontrado em estudo ${ }^{(22)}$ que identificou o maior número de notificações na Clínica Médica, seguida pela Clínica Pediátrica, Clínica Cirúrgica e, só depois, na UTI.

Verificou-se ainda, com base neste estudo que febre, aparecimento de placas eritematosas e prurido foram os sinais/sintomas mais frequentes, inclusive mais evidentes nessas reações (RFNH e RA). Tais evidências coincidem com aquelas encontradas em estudo ${ }^{(20)}$ que traz, como três principais sinais/sintomas mais notificados: urticária, calafrios e febre. Pesquisa ${ }^{(14)}$ relata que os sinais mais percebidos foram febre, dispneia e urticária. Outro estudo ${ }^{(24)}$ relata febre, calafrios e/ou sudorese e lesões em derme como sinais mais presentes nas notificações. 
Ao averiguar os dados deste estudo, constatou-se que os hemocomponentes mais envolvidos em RTs imediatas foram o concentrado de hemácias, seguido de concentrado de plaquetas e de plasma fresco congelado e, por fim, crioprecipitado. Esta frequência de transfusões é semelhante à encontrada em estudo desenvolvido no Norte de Minas Gerais ${ }^{(20)}$. O CH foi também identificado como o hemocomponente mais transfundido, porém o segundo hemocomponente mais transfundido, foi o concentrado de plasma fresco e não o concentrado de plaquetas e, por fim, o crioprecipitado ${ }^{(14,22)}$.

Como limitações do estudo, há que se destacar a disponibilidade dos dados apenas em versão impressa, o que demandou maior tempo para a coleta e pode dificultar outros estudos que requeiram informações de maior recorte temporal.

Espera-se que os resultados apresentados possam subsidiar o desenvolvimento de novos estudos sobre os eventos adversos apresentados por receptores de hemocomponentes, contribuindo para a Saúde Pública, uma vez que a reflexão e a discussão sobre a segurança transfusional poderão potencialmente produzir efeitos para a melhoria da qualidade da assistência prestada em instituições que realizam terapia transfusional, além de agregar novos conhecimentos aos profissionais de saúde que atuam nessa área.

\section{Conclusão}

Este estudo buscou identificar e discutir a ocorrência de RTs imediatas, considerando o tipo de hemocomponente transfundido, demanda e capacidade de atendimento em um Hospital Universitário no estado da Bahia, Brasil.

Identificou-se que os hemocomponentes transfundidos foram de concentrado de hemácias, de pool de plaquetas, plasma fresco ou pool de crioprecipitados; as RTs imediatas mais notificadas à Anvisa foram as Reações Febris Não Hemolítica (RFNH), seguidas por Reação Alérgica (RA), notificações como Sobrecarga Volêmica (SCV) e Injúria Pulmonar não Cardiogênica.
O hospital estudado apresentou capacidade de atendimento da demanda transfusional.

Os resultados e as reflexões apresentados aqui poderão estimular novos estudos que permitam melhor avaliar e compreender as reações transfusionais, assim como estimular/assegurar práticas que promovam maior segurança dos pacientes submetidos à terapia transfusional.

Cabe destacar a importância da informatização dos dados, visto que o registro apenas na forma impressa limita o acesso rápido, bem como pode inviabilizar estudos que pretendam maior recorte temporal para análise, uma vez que demandará mais tempo para a coleta.

\section{Colaborações:}

1 - concepção, projeto, análise e interpretação dos dados: Marta Suzin Cercato e Mariluce Karla Bomfim de Souza;

2 - redação do artigo e revisão crítica relevante do conteúdo intelectual: Marta Suzin Cercato e Mariluce Karla Bomfim de Souza;

3 - aprovação final da versão a ser publicada: Marta Suzin Cercato e Mariluce Karla Bomfim de Souza.

\section{Referências}

1. Pimentel MA. A questão do sangue: rumos das políticas públicas de hemoterapia no Brasil e no exterior [tese]. Rio de Janeiro: Instituto de Medicina Social, Universidade do Estado do Rio de Janeiro; 2006.

2. D'innocenzo $\mathrm{M}$, Adami NP, Cunha ICK. O movimento pela qualidade nos serviços de saúde e enfermagem. Rev bras enferm. 2006;59(1):29-47. DOI: http://dx.doi.org/10.1590/ S0034-71672006000100016

3. Brasil. Ministério da Saúde. Agência Nacional de Vigilância Sanitária. Resolução da Diretoria Colegiada - RDC no. 34, de 11 de junho de 2014. Dispõe sobre as Boas Práticas no Ciclo do Sangue [Internet]. Brasília (DF); 2014 [cited 2018 Jun 20]. Available from: https://saude.rs.gov.br/ upload/arquivos/carga20170553/04145350-rdcanvisa-34-2014.pdf 
4. Brasil. Ministério da Saúde. Agência Nacional de Vigilância Sanitária. Marco Conceitual e Operacional de Hemovigilância. Guia para a Hemovigilância no Brasil [Internet]. Brasília (DF); 2015 [cited 2018 Jun 18]. Available from: https:// www.hemocentro.unicamp.br/arquivos/2018/09/ Guia-Hemovigilancia-Marco-conceitual_ Anvisa2015-1.pdf

5. Berro $\mathrm{M}$, Insagaray $\mathrm{J}$, Barindelli $\mathrm{P}$, Sosa $\mathrm{E}$, Marcalain V, González J, et al. Implementación de un sistema de hemovigilancia en el Hospital de Clínicas de Uruguay. Rev Méd Urug [Internet]. 2016 [cited 2018 Jun 2];32(4):268-73. Available from: http://www.scielo.edu.uy/scielo.php?script=sci_ abstract\&pid=S1688-03902016000400005\&lng=es\& $\mathrm{nrm}=\mathrm{iso \& t} \operatorname{lng}=\mathrm{pt}$

6. Rogers MAM, Rohde JM, Blumberg N. Haemovigilance of reactions associated with red blood cell transfusion: comparison across 17 Countries. Vox Sang. 2016 Apr;110(3):266-77. DOI: 10.1111/vox.12367

7. Menis M, Forshee RA, Anderson SA, Mckean S, Gondalia R, Warnock R, et al. Febrile non-haemolytic transfusion reaction occurrence and potential risk factors among the U.S. elderly transfused in the inpatient setting, as recorded in Medicare databases during 2011-2012. Vox Sang. 2015 Apr;108(3):251-61. DOI: 10.1111/ vox. 12215

8. Lafeuillade $\mathrm{B}, \mathrm{Eb} \mathrm{F}$, Ounnoughene $\mathrm{N}$, Petermann R, Daurat G, Huyghe G, et al. Residual risk and retrospective analysis of transfusion-transmitted bacterial infection reported by the French National Hemovigilance Network from 2000 to 2008. Transfusion. 2015 Mar;55(3):636-46. DOI: 10.1111/trf.12883

9. Menis M, Anderson SA, Forshee RA, Mckean S, Johnson C, Holness L, et al. Transfusion-associated circulatory overload (TACO) and potential risk factors among the inpatient US elderly as recorded in Medicare administrative databases during 2011. Vox Sang. 2014 Feb;106(2):144-52. DOI: 10.1111/ vox. 12070

10. Piccin A, Cronin M, Brady R, Sweeney J, Marcheselli L, Lawlor E. Transfusion-associated circulatory overload in Ireland: a review of cases reported to the National Haemovigilance Office 2000 to 2010. Transfusion. 2015 Jun;55(6):1223-30. DOI: $10.1111 /$ trf.12965

11. Harvey AR, Basavaraju SV, Chung K-W, Kuehnert MJ. Transfusion-related adverse reactions reported to the National Healthcare Safety Network Hemovigilance Module, United States, 2010 to 2012. Transfusion. 2015 Apr;55(4): 709-18. DOI: $10.1111 /$ trf.12918

12. Alexei MM, Rivero Jiménez RA, Fernández Delgado N. Efectos adversos en la cadena transfusional en el Instituto de Hematología e Inmunología. Rev Cubana Hematol Inmunol Hemoter [Internet]. 2015 Set [cited 2018 Feb 25];31(3):288-300. Available from: http://scielo.sld.cu/scielo.php?script=sci_ arttext\&pid=S0864-02892015000300007

13. Parmar N, Pendergrast J, Lieberman L, Lin Y, Callum J, Cserti-Gazdewich C. The association of fever with transfusion-associated circulatory overload. Vox Sang. 2017 Jan;112(1):70-8. DOI: $10.1111 /$ vox. 12473

14. Beserra MPP, Portela MP, Monteiro MP, Façanha MC, Adriano LA, Fonteles MMF. Reações transfusionais em um hospital cearense acreditado: uma abordagem em hemovigilância. Arq Med [Internet]. 2014 [cited 2019 Mar 10];28(4):99-103. Available from: http://www.scielo.mec.pt/scielo.php?script=sci_ arttext\&pid=S0871-34132014000400002

15. Pahuja S, Puri V, Mahajan G, Grupta P, Jain M. Reporting adverse transfusion reactions: A retrospective study from tertiary care hospital from New Delhi, India. Asian J Transfus Sci. 2017;11(1):6-12. DOI:10.4103/0973-6247.200779

16. Brasil. Ministério da Saúde. Agência Nacional de Vigilância Sanitária. Relatório de Hemovigilância 2015 [Internet]. Brasília (DF); 2016 [cited 2019 Jun 13]. Available from: https://www.gov.br/anvisa/ pt-br/assuntos/fiscalizacao-e-monitoramento/ hemovigilancia/publicacoes/hemovigilancia-nobrasil-relatorio-consolidado-2007-2015.pdf/view

17. Brasil. Ministério da Saúde. Agência Nacional de Vigilância Sanitária. 6o Boletim de Produção Hemoterápica. Hemoprod 2017 [Internet]. Brasília (DF); 2018 nov [cited 2019 Mar 24]. Available from: https://www.gov.br/anvisa/ pt-br/centraisdeconteudo/publicacoes/sanguetecidos-celulas-e-orgaos/producao-e-avaliacaode-servicos-de-hemoterapia/6deg-boletim-deproducao-hemoterapica-2018.pdf

18. Durães ATG, Pereira LB, Ponciano MM, Versiani CC. A incidência de reações transfusionais imediatas em pacientes receptores em um hospital universitário. EFDeportes.com, Rev Digital [Internet]. 2013 
Ene [cited 2018 Jan 10];Año 17(176). Available from: https://www.efdeportes.com/efd176/aincidencia-de-reacoes-transfusionais-imediatas. htm\#: :text=As\%20rea\%C3\%A7\%C3\%B5es\%20 adversas $\% 20$ imediatas $\% 20$ ocorridas,de $\% 20$ longo\%20prazo\%20de\%20mortalidade

19. Saito M. Hemovigilância: Eventos Transfusionais Adversos antes e após a implantação do Comitê Transfusional Hospitalar [Internet]. [dissertação]. Londrina: Universidade Estadual de Londrina; 2010 [cited 2019 Feb 20]. Available from: http://bdtd.ibict.br/vufind/Record/UEL_8b7 88c6b428fea3991d3c08d298d6a65

20. Macedo ED, Silveira VMJ, Athayde LA. Índice de reação transfusional em pacientes submetidos a transfusão em um hemocentro do norte de Minas Gerais. RBPeCS [Internet]. 2015 [cited 2018 Jun 2];2(2):54-9. Available from: http://revistas.icesp. br/index.php/RBPeCS/article/view File/49/39

21. Callera F, Silva ACO, Moura AF, Melo DB, Melo CMTP. Description of acute transfusion reaction in a Brasilian transfusion service. Rev Bras Hematol Hemoter. 2004;26(2):78-83. DOI: https://doi.org/10.1590/S1516-84842004000200003
22. Farias TLV. Epidemiologia das reações transfusionais imediatas no Hospital Napoleão Laureano [Internet]. [Trabalho de Conclusão de Curso de Farmácia]. João Pessoa (PB): Universidade Federal da Paraíba; 2017 [cited 2019 Apr 20]. Available from: https://repositorio.ufpb.br/jspui/ bitstream/123456789/3561/1/TLVF08062017.pdf

23. Brasil. Ministério da Saúde. Secretaria de Gestão do Trabalho e da Educação na Saúde. Departamento de Gestão do Trabalho na Saúde. Técnico em hemoterapia: livro texto [Internet]. Brasília (DF); 2013 [cited 2019 Mar 25]. Available from: http://bvsms.saude.gov.br/bvs/publicacoes/ tecnico_hemoterapia_livro_texto.pdf

24. Grandi JL, Grell MC, Areco KCN, Barbosa DA. Hemovigilance: the experience of transfusion reaction reporting in a Teaching Hospital. Rev esc enferm USP. 2018;52:e03331. DOI: https://doi. org/10.1590/s1980-220x2017010603331

25. Zago MA, Falcão RP, Pasquini R. Hematologia: fundamentos e prática. São Paulo: Atheneu; 2013.

Recebido: 14 de novembro de 2020 Aprovado: 10 de maio de 2021 Publicado: 8 de junho de 2021

A Revista Baiana de Enfermagem utiliza a Licença Creative Commons - Atribuição-NãoComercial 4.0 Internacional. https://creativecommons.org/licenses/by-nc/4.0/ Este artigo é de acesso aberto distribuído sob os termos da Licença Creative Commons (CC BY-NC). Esta licença permite que outros remixem, adaptem e criem a partir do seu trabalho para fins não comerciais. Embora os novos trabalhos tenham de lhe atribuir o devido crédito e não possam ser usados para fins comerciais, os usuários não têm de licenciar esses trabalhos derivados sob os mesmos termos. 